\title{
Postural control in chronic obstructive pulmonary disease: a systematic review
}

\author{
This article was published in the following Dove Press journal: \\ International Journal of COPD \\ 29 June 2015 \\ Number of times this article has been viewed
}

\author{
EF Porto ${ }^{1,2}$ \\ AAM Castro ${ }^{1,3}$ \\ VGS Schmidt ${ }^{4}$ \\ HM Rabelo ${ }^{4}$ \\ C Kümpel ${ }^{2}$ \\ OA Nascimento 5 \\ JR Jardim ${ }^{5}$
}

'Pulmonary Rehabilitation Center, Federal University of São Paulo, ${ }^{2}$ Adventist University, São Paulo, ${ }^{3}$ Federal University of Pampa, Rio Grande do Sul, ${ }^{4}$ Pulmonary Rehabilitation Center, Adventist University, ${ }^{5}$ Respiratory Diseases, Pulmonary Rehabilitation Center, Federal University of São Paulo, São Paulo, Brazil
Correspondence: José R Jardim Respiratory Diseases, Pulmonary Rehabilitation Center, Federal University of São Paulo, Rua Botucatu 740, $3^{\circ}$ andar, 04023-062, São Paulo, Brazil Fax +55 II 5572430 I Email jardimpneumo@gmail.com
Abstract: Patients with chronic obstructive pulmonary disease (COPD) fall frequently, although the risk of falls may seem less important than the respiratory consequences of the disease. Nevertheless, falls are associated to increased mortality, decreased independence and physical activity levels, and worsening of quality of life. The aims of this systematic review was to evaluate information in the literature with regard to whether impaired postural control is more prevalent in COPD patients than in healthy age-matched subjects, and to assess the main characteristics these patients present that contribute to impaired postural control.

Methods: Five databases were searched with no dates or language limits. The MEDLINE, PubMed, EMBASE, Web of Science, and PEDro databases were searched using "balance", "postural control", and "COPD" as keywords. The search strategies were oriented and guided by a health science librarian and were performed on March 27, 2014. The studies included were those that evaluated postural control in COPD patients as their main outcome and scored more than five points on the PEDro scale. Studies supplied by the database search strategy were assessed independently by two blinded researchers.

Results: A total of 484 manuscripts were found using the "balance in COPD or postural control in COPD" keywords. Forty-three manuscripts appeared more than once, and 397 did not evaluate postural control in COPD patients as the primary outcome. Thus, only 14 studies had postural control as their primary outcome. Our study examiners found only seven studies that had a PEDro score higher than five points. The examiners' interrater agreement was $76.4 \%$. Six of those studies were accomplished with a control group and one study used their patients as their own controls. The studies were published between 2004 and 2013.

Conclusion: Patients with COPD present postural control impairment when compared with age-matched healthy controls. Associated factors contributing to impaired postural control were muscle weakness, physical inactivity, elderly age, need for supplemental oxygen, and limited mobility.

Keywords: posture, balance, chronic obstructive pulmonary disease, postural control, systematic review

\section{Introduction}

Chronic obstructive pulmonary disease (COPD) is a preventable and treatable illness with effects on the whole body that can contribute to loss of functional capacity for the patient. ${ }^{1}$

The Global Initiative for Chronic Obstructive Lung Disease (GOLD) document $(2011)^{1}$ advises proper attention to not only respiratory treatment but also to extrarespiratory consequences in COPD patients. According to some studies, impaired balance may be one important extrarespiratory morbidity leading to loss of functional independence and falls. ${ }^{2}$ However, postural control does not figure in the GOLD report as 
an important disease-related association, and this is an important aspect that should be assessed.

Loss of postural control is one of the most common comorbidities in elderly subjects. ${ }^{2}$ It is known that $30 \%$ of subjects over 60 years of age fall at least once a year, and that the fall rate increases up to $45 \%$ in subjects over 70 years of age. ${ }^{2}$ Impaired postural control is more frequent when the elderly person has a chronic disease. The PLATINO study showed that the prevalence of COPD increases in older subjects. ${ }^{3}$ Thus, there is some evidence that can explain a possible association between aging, COPD, and impaired postural control that might predispose these patients to an increased risk of falls.

Falls in elderly subjects have serious consequences in terms of functional independence, social interaction, and life expectancy. ${ }^{4,5}$ Risk factors for falls in the elderly, such as lower limb muscle weakness, labyrinthine disease, functional performance deficit, and the capacity to align the body once out of balance are well documented. ${ }^{4,5}$ These risk factors are also common in COPD patients. ${ }^{6,7}$ Although the risk of falls may seem less important than the respiratory consequences of the disease, falls are associated with increased mortality, decreased independence and level of physical activity, and worsening of quality of life in both COPD patients and healthy age-matched subjects. ${ }^{8-10}$ In addition, the consequences of falls are expensive for the health care system. ${ }^{10}$ Therefore, assessment of the causes of impaired postural control in COPD patients may contribute to preventing the consequences of such falls. Roig et $\mathrm{al}^{2}$ and Beauchamp et $\mathrm{al}^{9}$ have already shown that COPD patients may have impaired postural control, but the relevant risk factors are still unknown.

Therefore, the aim of this systematic review was to evaluate the literature to determine if impaired postural control is more prevalent in COPD patients than in healthy age-matched subjects, and as the novel finding, we also aimed to assess the main characteristics that contribute to impaired postural control in these patients.

\section{Methods}

This study was a systematic review of the prevalence of impaired postural control in COPD patients, without metaanalysis. The protocol was submitted and approved by the ethics committee of our University and all patients gave their written consent. Postural control is usually assessed by means of the force platform, being the center of vertical force calculated from the ground-reaction forces projected from the body, and is the center of the distribution of the total force applied to the supporting surface. ${ }^{4}$ It reflects the trajectory of the center of mass and the amount of torque applied at the support surface to control body mass acceleration. ${ }^{9}$ Measurement of certain variables in COPD patients enables us to detect and qualify sudden changes, and is clinically useful for detecting and qualifying sensorimotor postural deficiencies (eg, impaired postural control) such as increased postural sway. Usually, the higher the mean radius of the distribution of center of vertical force, the poorer the ability to control balance. ${ }^{4,9}$

\section{Search strategy}

Seven databases (LILACS, MEDLINE, PubMed, SciELO, EMBASE, Web of Science, and PEDro) were searched with no dates or language limits. However, only English language studies were found at the time of searching. We used Boolean logic with AND and OR operators, the MeSH terms of the Health Care subheading within the MeSH Tree Structures, and "balance", "postural control", and "COPD" as the MeSH terms that best fit our search strategy. The searches were guided by a health science librarian and performed on March 27, 2014.

Studies yielded by the database search strategy were assessed independently in a blinded manner by two researchers. Both researchers closely evaluated the inclusion and exclusion criteria, treatment methods, interventions, target sample, and study design. Studies without diagnostic criteria for COPD and studies with qualitative assessments were excluded. All studies were firstly screened by title and abstract. After eliminating duplicated studies, the two independent examiners read the paper abstracts following the previous established criteria. The agreement rate on study exclusion was $89 \%$. The included manuscripts were read and assessed according to the PEDro criteria. For this analysis, the examiners' interrater agreement was $89.7 \%$. Any disagreement between the examiners was resolved by a technical discussion.

Only studies that evaluated postural control in COPD patients as their main outcome and that scored more than five points on the PEDro scale were included. ${ }^{11}$ The five-point score was established as the threshold on the PEDro scale because this limit is considered to determine whether a study is well designed or not.

\section{Assessment of methodological quality}

We used the PEDro ${ }^{11}$ scale to assess the methodological quality of the studies. This scale was developed to validate clinical trials and is one of the most commonly used scales worldwide. 
The total score on the PEDro scale may reach eleven points. For every criterion on this scale, a one or zero score is attributed. "The score can only be attributed when a criteria is clearly fulfilled. If there is a no possibility to fulfill it no score are to be given." ${ }^{\prime 1}$ The PEDro score uses the following assessment criteria: specific eligibility; intergroup randomization; hidden group allocation; similarity of intergroup prognostic indicators; blinded groups; blinded examiners; blinded assessors; a dropout rate lower than $15 \%$; treatment or, at least, intention to treat; intergroup statistical comparison; cutoff points and variability for at least one key outcome. Every criterion is considered as one score except for the first one.

\section{Results}

Figure 1 shows the manuscript selection procedure from screening to final analysis. Initially, 484 manuscripts were found using the keywords "balance in COPD" or "postural control in COPD". Of those, 397 studies were excluded

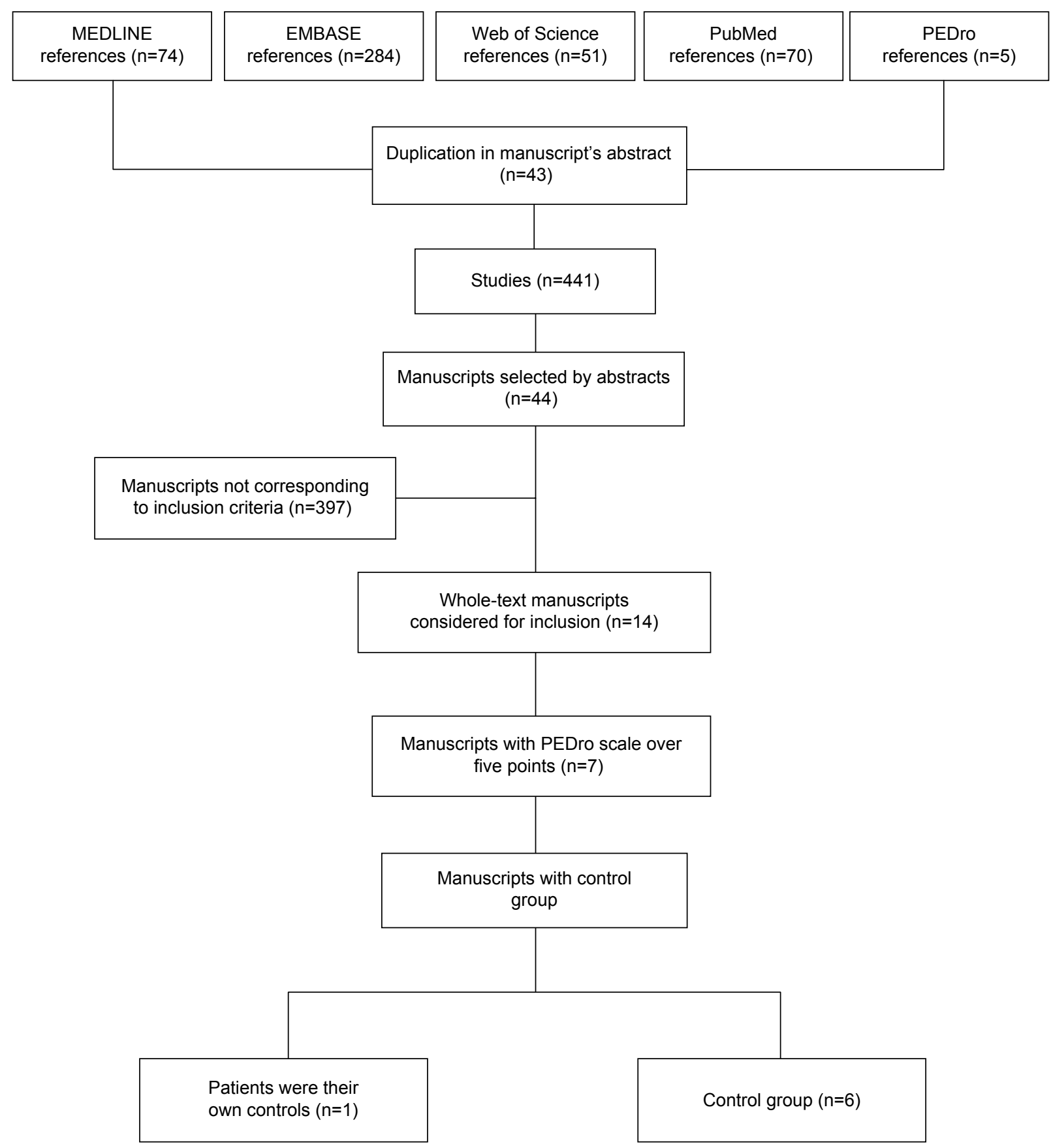

Figure I Flow diagram of manuscript selection procedure. 
Table I Characterization of studies included in the final analysis

\begin{tabular}{|c|c|c|c|c|c|c|c|}
\hline Reference & $\begin{array}{l}\text { PEDro } \\
\text { score }\end{array}$ & Setting & Study design & Keywords & $\begin{array}{l}\text { Outcome } \\
\text { variables }\end{array}$ & $\begin{array}{l}\text { COPD/ } \\
\text { controls (n) }\end{array}$ & $\begin{array}{l}\text { Assessment } \\
\text { method }\end{array}$ \\
\hline Rocco et $\mathrm{al}^{13}$ & 9 & $\begin{array}{l}\text { São Paulo } \\
\text { (Brazil) }\end{array}$ & Cross-sectional & Balance, COPD & $\begin{array}{l}\text { Dynamic balance, } \\
\text { monosynaptic } \\
\text { reflexes, } \\
\text { peripheral muscle } \\
\text { strength, SST }\end{array}$ & $22 / 16$ & $\begin{array}{l}\text { Tinetti test, strength } \\
\text { platform }\end{array}$ \\
\hline Butcher et $\mathrm{al}^{12}$ & 8 & $\begin{array}{l}\text { Saskatoon } \\
\text { (Canada) }\end{array}$ & Cross-sectional & $\begin{array}{l}\text { COPD, disease } \\
\text { severity, balance } \\
\text { assessment, } \\
\text { functional effects }\end{array}$ & $\begin{array}{l}\text { Balance, } \\
\text { coordination and } \\
\text { mobility }\end{array}$ & $|5 /| 5 / 2 \mid$ & $\begin{array}{l}\text { TUG test, fast } \\
\text { gait speed test, } \\
\text { posturography, } \\
\text { and finger-to-nose } \\
\text { and toe-tapping } \\
\text { coordination tests }\end{array}$ \\
\hline Smith et $\mathrm{al}^{20}$ & 8 & $\begin{array}{l}\text { Queensland } \\
\text { (Australia) }\end{array}$ & Cross-sectional & $\begin{array}{l}\text { Postural control, } \\
\text { COPD, balance, } \\
\text { exercise, } \\
\text { respiratory } \\
\text { conditions }\end{array}$ & $\begin{array}{l}\text { Postural control, } \\
\text { lumbar spine and } \\
\text { hip motion }\end{array}$ & $12 / 12$ & $\begin{array}{l}\text { Force plate to } \\
\text { record center } \\
\text { of pressure } \\
\text { displacement, } \\
\text { inclinometers }\end{array}$ \\
\hline Beauchamp et al ${ }^{9}$ & 8 & $\begin{array}{l}\text { Toronto } \\
\text { (Canada) }\end{array}$ & Cross-sectional & $\begin{array}{l}\text { Fall, COPD, } \\
\text { balance, } \\
\text { rehabilitation }\end{array}$ & $\begin{array}{l}\text { Postural control, } \\
\text { risk of fall, skill, } \\
\text { incidence of falls, } \\
\text { exercise tolerance }\end{array}$ & 39 & $\begin{array}{l}\text { TUG, BBS, 6MWT, } \\
\text { ABC, MRC }\end{array}$ \\
\hline $\begin{array}{l}\text { Beauchamp } \\
\text { et al }{ }^{15}\end{array}$ & 6 & $\begin{array}{l}\text { Toronto } \\
\text { (Canada) }\end{array}$ & Prospective & $\begin{array}{l}\text { Accidental } \\
\text { falls, postural } \\
\text { balance, COPD, } \\
\text { rehabilitation }\end{array}$ & $\begin{array}{l}\text { Postural control, } \\
\text { tolerance exercise }\end{array}$ & 38 & CRQ \\
\hline Beauchamp et al ${ }^{17}$ & 7 & $\begin{array}{l}\text { Toronto } \\
\text { (Canada) }\end{array}$ & Cross-sectional & - & $\begin{array}{l}\text { Balance, physical } \\
\text { activity and lower } \\
\text { extremity muscle } \\
\text { strength }\end{array}$ & $37 / 20$ & $\begin{array}{l}\text { Best test, physical } \\
\text { activity scale for the } \\
\text { elderly, isokinetic } \\
\text { dynamometer }\end{array}$ \\
\hline Janssens et $\mathrm{al}^{21}$ & 7 & $\begin{array}{l}\text { Leuven } \\
\text { (Belgium) }\end{array}$ & Cross-sectional & - & $\begin{array}{l}\text { Postural control, } \\
\text { ankle and back } \\
\text { muscle vibration, } \\
\text { inspiratory muscle } \\
\text { strength }\end{array}$ & $18 / 18$ & \\
\hline
\end{tabular}

Abbreviations: SST, sit-to-stand test; TUG,Timed Up and Go; BBS, Berg Balance Scale; ABC, Activities-specific Balance Confidence; MRC, Medical Research Council dyspnea score; 6MWT, Six-minute walking test; CRQ, Chronic Respiratory Questionnaire; COPD, chronic obstructive pulmonary disease.

because they did not evaluate postural control in COPD patients as their main outcome and did not score more than five points on the PEDro scale. Only 14 studies had postural controls as their primary outcome. ${ }^{1,2,7,10,12,13-23}$ Table 1 shows the manuscripts $9,12,13,16,17,20,22$ that were included in the final analysis. According to the PEDro scale, the manuscript scores ranged from six to nine points. Cross-sectional studies comprised $87.5 \%$ of the trials, and the most commonly assessed outcome variables were postural control, mobility, coordination, strength muscle, exercise tolerance, physical activity, and risk of falling. The methods most frequently used to assess the impairment of postural control were the Berg Balance Scale (BBS), the Balance Evaluation Systems Test (BESTest), the Tinetti scale, the strength platform, and posturography. Descriptions of these methods can be found elsewhere. ${ }^{4,18,23}$
Table 2 shows the main characteristics of the studies including main author, subject age, forced expiratory volume in the first second, fall rates, and correlations with impaired postural control.

Table 3 shows the assessment of dynamic postural control (eg, assessment of postural control while accomplishing any limb or trunk movement) in COPD patients and controls. In all seven studies, the COPD patients showed loss of dynamic postural control when compared with healthy age-matched subjects. For postural control assessment, two studies used the BBS, two used the Activities-specific Balance Confidence test, two used the Timed Up and Go (TUG) test, and one used the BESTest with Clinical Instrument Assess and the Tinetti scale. The main conclusions of the authors were that COPD patients present neurofunctional alteration, motor incoordination, and loss of postural control when performing 
Table 2 Study identification and sample characterization

\begin{tabular}{|c|c|c|c|c|}
\hline Reference & Age (years) & FEV $_{1}(\%)$ & Falls (\%) & Impaired postural control correlations \\
\hline Rocco et $\mathrm{al}^{13}$ & $70 \pm 6.66$ & $39.88 \pm 8.69$ & - & BODE index \\
\hline Butcher et $\mathrm{al}^{12}$ & $69.5 \pm 8.5$ & $29.87 \pm 3.73$ & - & Disease severity, activity levels \\
\hline Smith et $\mathrm{a}^{20}$ & $64.6(53-80)$ & $33.1 \pm 12.7$ & - & Increased trunk muscle activity and compromised postural control \\
\hline Beauchamp et $\mathrm{al}^{9}$ & $7 I . I \pm 6.8$ & $41.5 \pm 17$ & 46 & Need for supplementary oxygen in patients \\
\hline Beauchamp et al ${ }^{15}$ & $69.8 \pm 10.3$ & $46.3 \pm 22.3$ & 41 & Change in physical capacity (6MWT) or dyspnea scores (CRQ) \\
\hline Beauchamp et al ${ }^{17}$ & $71 \pm 7$ & $39.4 \pm 16.3$ & 51 & $\begin{array}{l}\text { Low self-reported physical activity levels and lower } \\
\text { extremity muscle weakness }\end{array}$ \\
\hline Janssens et $\mathrm{al}^{2 !}$ & $64 \pm 7$ & $50 \pm 18$ & - & Inspiratory muscle weakness and proprioceptive dysfunction \\
\hline
\end{tabular}

Abbreviations: FEV , forced expiratory volume in first second; BODE, Body-mass index, airflow Obstruction, Dyspnea, and Exercise; 6MWT, Six-minute walking test; CRQ, Chronic Respiratory Questionnaire.

daily tasks. Further, these patients also have an increased risk of falls, a lower level of physical activity, muscle weakness, loss of proprioceptive control, and higher body oscillation frequency.

\section{Discussion}

The main findings of this systematic review are as follows. First, impairment of postural control is more frequent in COPD patients than in healthy age-matched subjects. Second, impairment of postural control is associated with loss of muscle strength. Third, impairment of postural control is associated with a lower functional capacity and independence and a lack of physical activity.

Impairment of postural control in the elderly is well established. ${ }^{8,19,23-25}$ However, postural control has only been studied in COPD patients in the past few years and its assessment has not been standardized in this population, which has led to inconsistent results in the studies.

Hamilton et $\mathrm{al}^{24}$ showed that the latency time for the Achilles and patellar tendon reflex is longer in COPD patients than in control subjects. The authors believe that this nerve conduction delay is secondary to peripheral muscle

Table 3 Outcomes reported by the included studies

\begin{tabular}{|c|c|c|c|c|c|c|}
\hline Reference & BBS control & $\begin{array}{l}\text { BESTest } \\
\text { (score) }\end{array}$ & $\begin{array}{l}\text { ABC } \\
\text { (score) }\end{array}$ & TUG test & Other & Conclusion \\
\hline Rocco et $\mathrm{al}^{13}$ & - & - & - & - & $\begin{array}{l}26.86 / 27.8 I \\
(P<0.05)\end{array}$ & $\begin{array}{l}\text { COPD patients had functional and } \\
\text { neurophysiological alterations in } \\
\text { comparison with controls }\end{array}$ \\
\hline Butcher et al ${ }^{12}$ & - & - & - & $\begin{array}{l}7.2 / 5.35 \\
(P<0.05)\end{array}$ & - & $\begin{array}{l}\text { COPD exhibit deficiencies in functional } \\
\text { balance, coordination, and mobility tasks }\end{array}$ \\
\hline Smith et $\mathrm{a}^{20}$ & - & - & - & - & - & $\begin{array}{l}\text { There is reduced control of balance in the } \\
\text { mediolateral direction and increased risk } \\
\text { of falls in COPD patients }\end{array}$ \\
\hline Beauchamp et al ${ }^{9}$ & $\begin{array}{l}45.2 / 48.8 \\
(P<0.042)\end{array}$ & - & $\begin{array}{l}65.8 / 81.7 \\
(P<0.002)\end{array}$ & $\begin{array}{l}|7 /| 4 \\
(P<0.024)\end{array}$ & - & $\begin{array}{l}\text { There are differences in balance, } \\
\text { functional mobility, and balance } \\
\text { confidence between fallers and nonfallers } \\
\text { in patients with COPD }\end{array}$ \\
\hline Beauchamp et al ${ }^{15}$ & 46.9 & - & 74.3 & 15.7 & - & $\begin{array}{l}\text { PR was associated with minor changes in } \\
\text { results of standard clinical tests of balance } \\
\text { and had no effect on balance confidence } \\
\text { in patients with COPD }\end{array}$ \\
\hline Beauchamp et al ${ }^{17}$ & $\begin{array}{l}48.7 / 54.9 \\
(P<0.00 I)\end{array}$ & $\begin{array}{l}70.7 / 91.9 \\
(P<0.001)\end{array}$ & $\begin{array}{l}75.8 / 95.8 \\
(P<0.001)\end{array}$ & - & - & $\begin{array}{l}\text { Impaired balance in COPD, deficiencies } \\
\text { in balance associated with low self- } \\
\text { reported physical activity levels and lower } \\
\text { extremity muscle weakness }\end{array}$ \\
\hline Janssens et $\mathrm{al}^{21}$ & - & - & - & - & - & $\begin{array}{l}\text { Patients with COPD, especially those } \\
\text { with inspiratory muscle weakness, } \\
\text { increased their reliance on ankle muscle } \\
\text { proprioceptive signals and decreased their } \\
\text { reliance on back muscle proprioceptive } \\
\text { signals during balance control }\end{array}$ \\
\hline
\end{tabular}

Abbreviations: PR, pulmonary rehabilitation; COPD, chronic obstructive pulmonary disease; BBS, Berg Balance Scale; TUG, Timed Up and Go; ABC, Activities-specific Balance Confidence; BESTest, Balance Evaluation Systems Test. 
impairment in COPD patients, and this delay could affect the reaction time for correction of postural control.

Butcher et a ${ }^{12}$ assessed postural control in two groups of COPD patients, ie, with and without use of continuous oxygen therapy, and compared the results for both groups with those in healthy controls. They found that COPD patients had deficits in functional balance, coordination, and mobility tasks that were associated with disease severity or with differences in activity levels. The activities tested were the TUG test, the fast gait speed test, posturography, and the fingerto-nose and toe-tapping coordination tests. Patients who required supplemental oxygen showed worse coordination and a longer delay to complete the finger-to-nose test when compared with the healthy control group. The COPD oxygen group also had a greater sway index and peak sway index with eyes open while standing in the platform test than the healthy control group. In addition, the COPD oxygen group performed worse on the TUG test and on the fast gait speed test than the COPD group that did not require oxygen.

The most significant deficits in balance, coordination, and mobility were found in the oxygen-dependent group, but these findings should be interpreted cautiously because this group had more severe disease.

Smith et $\mathrm{al}^{20}$ found that COPD patients had increased displacement of mediolateral center of pressure and increased angular motion of the hip in the standing position when compared with healthy controls. Mediolateral center of pressure displacement was further increased in these patients during upper limb exercise, but was unchanged in controls. However, anteroposterior center of pressure displacement did not differ between the groups. The authors concluded that COPD patients have increased mediolateral center of pressure displacement at rest and during upper limb exercise, possibly as a result of increased respiratory demand given by the trunk muscles contraction.

It is also possible to consider the hypothesis that this mediolateral body oscillation in COPD patients may be due to thoracoabdominal asynchrony with an inadequate contribution of the thorax compartment to tidal volume that eases postural sway. ${ }^{7}$

Beauchamp et a ${ }^{16}$ showed that impaired postural control, evaluated by the BBS and TUG test, is frequently seen in COPD patients with a previous history of falls, a deficit in functional mobility, or a need for supplementary oxygen. They also found a small improvement in postural control (ie, improvement of BBS and TUG scores) after a 6-week multidisciplinary pulmonary rehabilitation program consisting of exercise training, breathing exercises, education, and psychological support.
Accordingly, they recommend that a balance assessment should be part of routine examination in COPD patients given their high prevalence of falls. Further, the authors state that, despite this initiative having yet to be fully explored, incorporation of specific balance training and fall prevention strategies may contribute to the comprehensive treatment of COPD patients.

Two years later, Beauchamp et al ${ }^{17}$ reported several other factors related to impaired postural control, ie, a decrease in muscle strength, advancing age, and decreased self-reported physical activity levels. The authors found that COPD patients had reduced balance scores on each component of the BESTest, with marked deficits (a 30\% reduction) in biomechanics, transitions, and gait. Lower BBS scores, balance confidence scores, and physical activity levels were also evident in patients with COPD when compared with control subjects. Normalized peak torque for the knee extensors and flexors, ankle plantar flexors, and dorsiflexors were reduced in patients with COPD when compared with controls.

The same study ${ }^{17}$ also found that muscle strength and selfreported physical activity explained $35 \%$ of the variance in postural control in COPD patients. Although not part of the regression model, a slower reaction time to recover postural control in response to any instability was also associated with impairment of postural control.

Janssens et al $^{22}$ assessed postural control in COPD patients when standing on a foamy surface, and also assessed their postural control strategy according to the patient's inspiratory muscle strength. During an upright stance on an unstable support surface, patients with COPD showed increased body sway in the anterior-posterior direction when compared with controls. The authors showed that ankle-steered postural control was the main strategy adopted by COPD patients while standing on an unstable surface. In addition, the authors divided their sample according to inspiratory muscle strength, and found that the subgroup of patients with weaker inspiratory muscles showed greater body sway and a more ankle-steered strategy during postural control.

Although these authors did not measure respiratory muscle fiber strength, they considered that this association occurred due to the fact that decreased inspiratory muscle strength would impair proprioceptive muscle function and therefore realignment of the patient's body.

This systematic review allows us to conclude that COPD patients have impairment of postural control when compared with healthy age-matched controls. In addition, many of the associated factors that contribute to impaired postural control, like muscle weakness, physical inactivity, and limited mobility are amenable to change with appropriate education. 
Although the study sample sizes were sufficient to detect differences between COPD patients and healthy age-matched controls for most of the outcomes, larger studies are required to confirm these findings.

\section{Author contributions}

All authors contributed toward data analysis, drafting and revising the paper and agree to be accountable for all aspects of the work.

\section{Disclosure}

The authors have no conflicts of interest to declare in relation to this work. They have no financial and personal relationships with other people or organizations that could inappropriately influence their work such as employment, consultancies, stock ownership, honoraria, paid expert testimony, speakers bureaus, retainers, patent applications/registrations, travel grants, or other funding. No tobacco company and/or pharmaceutical/other company funded any part of this manuscript. This study has not had any sponsorship and no medical writing/editorial assistance was given.

\section{References}

1. Rabe KF, Hurd S, Anzueto A, et al. Global Strategy for the Diagnosis, Management, and Prevention of Chronic Obstructive Pulmonary Disease: GOLD executive summary. Am J Respir Crit Care Med. 2007; 176:532-555.

2. Roig M, Eng JJ, Road JD, Reid WD. Falls in patients with chronic obstructive pulmonary disease: a call for further research. Respir Med. 2009;103:1257-1269.

3. Menezes AM, Perez-Padilla R, Jardim JR, et al. Chronic obstructive pulmonary disease in five Latin American cities (the PLATINO study): a prevalence study. Lancet. 2005;366:1875-1881.

4. Ganança FF, Gazzola JM, Ganança CF, Caovilla HH, Ganança MM, Cruz OL. Elderly falls associated with benign paroxysmal positional vertigo. Braz J Otorhinolaryngol. 2010;76:113-120.

5. Tinetti ME, Speechley M, Ginter SF. Risk factors for falls among elderly persons living in the community. N Engl J Med. 1988;319:1701-1707.

6. Bernard S, LeBlanc P, Whittom F, et al. Peripheral muscle weakness in patients with chronic obstructive pulmonary disease. Am J Respir Crit Care Med. 1998;158:629-634.

7. Gai J, Gomes L, Nobrega Ode T, et al. Factors related to falls of elderly women residents in a community. Rev Assoc Med Bras. 2010;56:327-332.

8. Castro AA, Kumpel C, Rangueri RC, et al. Daily activities are sufficient to induce dynamic pulmonary hyperinflation and dyspnea in chronic obstructive pulmonary disease patients. Clinics (Sao Paulo). 2012;67: 319-325.

International Journal of COPD

\section{Publish your work in this journal}

The International Journal of COPD is an international, peer-reviewed journal of therapeutics and pharmacology focusing on concise rapid reporting of clinical studies and reviews in COPD. Special focus is given to the pathophysiological processes underlying the disease, intervention programs, patient focused education, and self management protocols.
9. Beauchamp MK, Hill K, Goldstein RS, Goldstein RS, Janaudis-Ferreira T, Brooks D. Impairments in balance discriminate fallers from non-fallers in COPD. Respir Med. 2009;103:1885-1891.

10. Morello RT, Barker AL, Haines T, et al. In-hospital falls and fall-related injuries: a protocol for a cost of fall study. Inj Prev. 2013;19:363.

11. Maher CG, Sherrington C, Herbert RD, Moseley AM, Elkins M. Reliability of the PEDro scale for rating quality of randomized controlled trials. Phys Ther. 2003;83:713-721.

12. Butcher SJ, Meshke JM, Sheppard MS. Reductions in functional balance, coordination, and mobility measures among patients with stable chronic obstructive pulmonary disease. J Cardiopulm Rehabil. 2004;24:274-280.

13. Rocco CC, Sampaio LM, Stirbulov R, Corrêa JC. Neurophysiological aspects and their relationship to clinical and functional impairment in patients with chronic obstructive pulmonary disease. Clinics (São Paulo). 2011;66:125-129.

14. Annegarn J, Meijer K, Passos VL, et al. Problematic activities of daily life are weakly associated with clinical characteristics in COPD. $J \mathrm{Am}$ Med Dir Assoc. 2011;13:284-290.

15. Beauchamp MK, Brooks D, Goldstein RS. Deficits in postural control in individuals with COPD - emerging evidence for an important secondary impairment. Multidiscip Respir Med. 2010;5:417-421.

16. Beauchamp MK, O'Hoski S, Goldstein RS, Brooks D. Effect of pulmonary rehabilitation on balance in persons with chronic obstructive pulmonary disease. Arch Phys Med Rehabil. 2010;91:1460-1465.

17. Beauchamp MK, Sibley KM, Lakhani B, et al. Impairments in systems underlying control of balance in COPD. Chest. 2012;141:1496-1503.

18. Gazzola JM, Perracini MR, Ganança MM, et al. Functional balance associated factors in the elderly with chronic vestibular disorder. Braz J Otorhinolaryngol. 2006;72:683-690.

19. Kayacan O, Beder S, Deda G, Karnak D. Neurophysiological changes in COPD patients with chronic respiratory insufficiency. Acta Neurol Belg. 2001;101:160-165.

20. Smith MD, Chang AT, Seale HE, Walsh JR, Hodges PW. Balance is impaired in people with chronic obstructive pulmonary disease. Gait Posture. 2010;31:456-460.

21. Janssens L, Pijnenburg M, Claeys K, McConnell AK, Troosters T, Brumagne $S$. Postural strategy and back muscle oxygenation during inspiratory muscle loading. Med Sci Sports Exerc. 2013;45:1355-1362.

22. Janssens L, Brumagne S, McConnell AK, et al. Proprioceptive changes impair balance control in individuals with chronic obstructive pulmonary disease. PLoS One. 2013;8:e57949.

23. Bogle Thorbahn LD, Newton RA. Use of the Berg Balance Test to predict falls in elderly persons. Phys Ther. 1996;76:576-583.

24. Hamilton AL, Killian KJ, Summers E, Jones NL. Muscle strength, symptom intensity, and exercise capacity in patients with cardiorespiratory disorders. Am J Respir Crit Care Med. 1995;152:2021-2031.

25. De Troyer A, Leeper JB, McKenzie DK, Gandevia SC. Neural drive to the diaphragm in patients with severe COPD. Am J Respir Crit Care Med. 1997;155:1335-1134.

\section{Dovepress}

This journal is indexed on PubMed Central, MedLine and CAS. The manuscript management system is completely online and includes a very quick and fair peer-review system, which is all easy to use. Visit http://www.dovepress.com/testimonials.php to read real quotes from published authors. 